\title{
The theorical-methodological construction of theses and dissertations and their epistemological problems
}

\author{
RODRIGO DUTRA GOMES \\ Programa de Pós-Graduação em Geografia/PPGEO-CFCH-UFPE, Departamento de Ciências Geográficas, Av. Prof. \\ Moraes Rego, 1235, CFCH $5^{\circ}$ e $6^{\circ}$ andar, Cidade Universitária, Caixa Postal 7803, 50670-901 Recife, PE, Brazil
}

Manuscript received on December 22, 2017; accepted for publication on April 30, 2018

\begin{abstract}
How to cite: GOMES RD. 2019. The theorical-methodological construction of theses and dissertations and their epistemological problems. An Acad Bras Cienc 91: e20171020. DOI 10.1590/0001-3765201920171020.

Abstract: This essay discusses the problem of the lack of dialogue between theory/empirical reality in the construction of the theoretical structure of dissertations and doctorates in Human Sciences in Brazil; taking Geography as an example, Santos (2000) observed this problem, which persists at the national level. The proposal is to present the question and to suggest the relationship between theory/empirical reality coming of the dialogue with specific research questions. It is these research questions that will define the limitations, factors, agents, processes and structures that will be studied. The relationship between the construction of the theoretical references with specific problems allowing theoretical-methodological advances, thus adapting the reading of the general theory to empirical situations. This appropriation generates both methodological directions for how to treat the empirical and the understandings that will be used in the discussion of the results. The confrontation and discussion of the results will suggest affirmations, questions and new perceptions for the theory.
\end{abstract}

Key words: Empirical theory, research questions, methodological theory, human science.

\section{INTRODUCTION}

The deficient dialogue between theory and empirical reality is one of the main epistemological problems observed in dissertations and theses in Human Sciences in Brazil; this is confirmed in readings and the examination of postgraduate works. This is not necessarily a specific problem of Brazil; this is only our direct experience, actions and immediate observations. This deficiency causes delays in theoretical and methodological developments -

Correspondence to: Rodrigo Dutra Gomes

E-mail: rdutragomes@gmail.com

ORCid: http://orcid.org/0000-0001-6452-3933 despite the growth in the implementation of new graduate programs.

In the video "The Active Role of Geography: A Manifest", Professor Milton Santos (winner of the Vautrin Lud Prize in Geography) emphasized the persistence and generality of this problem. In the video, he complains that epistemology in Brazilian Geography is not adequately taught in postgraduate programs. This prejudices the students in their theses work; this problem was also observed in previous research on dissertations and theses in human sciences in the Digital Libraries of Theses and Dissertations of Brazilian universities. A problem also highlighted by the author concerns the disconnection between the discourses and 
arguments realized by the 'theoretical reference' and the empirical questions of research, restricting the development of theoretical and methodological proposals and the discussion of the results achieved. Consequently, the eminent geographer emphasized that, although well written, the 'theoretical reference' is not necessary because of the generic and contextual discourse on the themes not dialoguing directly with the empirical problems. This disconnection restricts the empirical discussions since the discussions proposed throughout the work cannot dialogue, reflect or make considerations about the specificities of the results achieved. The chapters, albeit discussing issues related to the problems, often do not communicate with the contents of the research. The work fails to form an 'argumentative body' where each chapter should adequately complement and connect with the understandings of others and give a direction of inquiry from the empirical - that is the method.

According to Santos (2000), "the work of the proposition of the great theory (...) must always be succeeded by the production of a minor theory that is only produced from empirical situations, at a lower level, to then you start working". However, those who intermediate the relationship between the theory and the empirical reality (in the "minor theory") are precisely the questions that will deal with the research of a certain problem (be it empirical or theoretical); that is, the research problem. In this movement, it was noticed that this problem of detachment between theory and empirical, emphasized by Santos 17 years ago, is due to the lack of dialogue between the construction of the theoretical and methodological development with the problems of the research. These are the problems that will discern the specific situations to be studied within the empirical (or theoretical) problem. It is these specific questions that will test the adequacy and capacity of theories to explain and interpret the unique situations of reality.

\section{MATERIALS AND METHODS}

Considering this context, this paper intends to share the discussions that have been carried out in the research group (epistemology and the history of geographical thought) on how to solve this question; in this case, presenting the role of the research problem and research questions in the construction of the theoretical reference of the works, as well as strengthening the theory and empiric relationship in the construction of research. It seeks to offer basic considerations to help the theoretical-methodological construction of studies. This essay based in reading dissertations and theses, and also in participating in examining theses and dissertations. Thus, in this text, the specific dissertations or theses that present the problems to be discussed will not be cited. Although it is easy to find them, this is to avoid constraints. Despite this lack of 'raw data', it is expected that if the issue is as frequent as is suggested, then it will not be difficult for colleagues to recognize; however, the generic examples that will be used are intended to express this 'hidden' data.

The text is organized as follows: (1) The theory and empirical evidence relationship is presented as being intermediated by the research problem and, mainly, by the specific research questions; (2) discussions about how research problems and research questions can direct the construction of the theoretical references; and (3) considerations about the construction of the theoreticalmethodological structure of the research questions, that is, on how the theoretical discussions guides in the methodological attitudes of "how" to study the empirical structure. This is not to construct a model, but to problematize and discuss the practice of constructing the theoretical references and to encourage more robust theoretical development in postgraduate works. 


\section{RESULTS AND DISCUSSION}

THE RELATIONSHIP BETWEEN THEORY/ EMPIRICAL EVIDENCE AND THE RESEARCH PROBLEMS

The relationship between theory and empirical evidence is generational, and any manual of scientific methodology states this (Bunge 1980, Goode and Hatt 1979). If there is no dialogue between the theory and empirical evidence, epistemological stagnation becomes inevitable. Being generational, theoretical divergence is due to a lack of congruence in the construction of this theoretical discourse with the empirical questions treated in each work - and vice versa. In the research, theoretical references present an ontology of the conception of reality and the previous epistemology as a way to identify this reality:

"The slowly emerging conceptual apparatus of the theory soon starts defining its own problems, and earlier problems, facts, and observations are either forgotten or pushed aside as irrelevant. This is an entirely natural development, and quite unobjectionable. (...) A comprehensive theory, after all, is supposed to contain also an ontology that determines what exists and thus delimits the domain of possible facts and possible questions. The development of science agrees with these considerations" (Feyerabend 1993, p. 155).

"A theoretical system is a way of organizing problems. All facts collected, all the analysis of these facts, [and] even the perception of the data themselves are ordered within some sort of theoretical framework (Goode and Hatt 1979, p. 31). (...) On the other hand, facts are also productive of theory: (1) facts help to initiate theories; (2) they lead to the reformulation of existing theory; (3) they cause the rejection of theories that do not fit the facts; (4) they change the focus and orientation of theory; and (5) they clarify and redefine theory (Goode and Hatt 1979, p. 8). (...) Facts, then, become a stimulus to the redefinition and clarification of theory even when they are in conformity with it. This process leads in turn to the reformulation of, theory and the discovery of new facts" (Goode and Hatt 1979, p. 16).

The empirical refers not only to the place or area of study, but largely to the selection of the aspects, factors, processes and elements of a given problem, discussed in terms of area or spatial processes (in the case of geography). Defining the areas and themes, among others, the research problems and the specific research questions will specify the context of what will be investigated, delimiting the scope and subjects of inquiry of a certain reality or theme. In other words, the negotiation between theory and the empirical evidence are the main references in the establishment of the research problem and the research question to be dealt with in a particular study or of a certain theme.

It is the problem and the research question that should dialogue and influence the theoretical reflections within the study. This, in turn, will increase the understandings and ways of perceiving and approaching this empirical evidence. A good or bad definition of the problem and of the research questions are some of the main obstacles that hinders the relationship between the theory and empirical questions, thus narrowing the relationship between the discourse of the reference theory, the methodological directions and the discussion of the empirical results of the research. It is the specificity of the research problems that will guide the researcher in the theoretical investigation and the construction of the theoretical reference; this, in turn, will guide and offer elements of 'how' (method) to deal with the empirical phenomenon. 
THE RESEARCH PROBLEM AND RESEARCH QUESTIONS: THE CONSTRUCTION OF A THEORETICAL FRAMEWORK

The research problem is the generic question that guides the research, and the research questions are the questions that will represent the overview and discernible context in which the research situates this problem. The development of the research has the problem as a central direction, but it is the specific research questions which will define the limits, factors, agents, processes and structures that will be studied, as well as to give direction to the theoretical and methodological approaches chosen for the research. Being an arbitrary and occasional act, in the sense of being influenced by the previous framework of the researcher, research group and by the occurrence of problems or their perception thereof, the definition of the research question is that it will guide the construction of the theoretical, methodological and technical framework to investigate the problem. In this sense, it is the research questions that delimit the scope, focus and direction of a certain problem. Moreover, there are several possible discernments for the selection of factors and processes of the same problem.

To illustrate, if we consider the repercussions of urban expansion of rural areas in a city as a research problem, the problems associated with these repercussions can be diverse and direct research to different paths. In the case of a problem in terms of the impact on biophysicalenvironmental systems, then aspects such as deforestation, pollution and silting of rivers and streams, biodiversity decline, erosion and pressure on springs could be required. Consequently, a category such as hydrographic basin, landscape or conceptual geosystem could be required for such an investigation (Christofoletti 1999). On the other hand, if the approach was geo-economical, then the problem would deal with issues such as space appreciation, private agents, land subdivisions, the re-functionalization of areas, urban infrastructure, director planning, spatial planning and public power; in such a case, the category of space, structuralist and functionalist methods, for example, could be used (Harvey 1973). However, if the approach was humanistic, the questions could deal with the repercussions experienced by people and the perceptions and experiences of the transformations in individuals' identity, memories, daily routines and attitudes (Buttimer 1982) could be requested for such an inquiry. Although they originate within the same generic problem, it is the specific research questions that will determine the scope and direction of the reflections, as well as help to suggest the approaches that the researcher or group may or may not arbitrarily choose. Although they refer to the same problem, and often identical information, there are three different directions with different focuses, and so they use different readings, approach, authors, theories, methods and techniques. It is this difference of focus in the research question that will construct the reference theory (of the readings and reflections) that will direct the investigation of the problem.

When the theoretical reference is constructed without reference to a specific research question, the readings and reflections often become disconnected from the research "focus" and specific issues. As a result, the discussions become broad, sometimes focusing on categories, notions and understandings related to the problem and other times focusing on broad issues being discussed in broad terms. However, there is very little dialogue associated with the research questions, which are the specific conditions selected in the empirical problem. Often, the research problems and research questions are satisfactorily clarified in the research introduction; however, in the development of the reference theory and the argumentation of the theoretical discourse they are inadequate for the scope of the research problems. This results, on the one hand, in a broad and discursive approach of the theme, categories 
and concepts, but it does not realize the discussion of the themes, notions and concepts with the specific empirical research questions, nor does it study them from the viewpoint of these categories or advance the theoretical-methodological construction. This is precisely what characterizes the distance between theory and fact (Goode and Hatt 1979, p. 7): Is it not empirical evidence that brings to the theory the specificities, singularities and ideologies that must be universalized (science), synthesized (dialectic) and interpreted (hermeneutics)?

If we take the problem of the repercussions of the urban expansion of rural areas and its three potential research questions, in the first case, the environmental focus, what is observed in the works is the discourse of the reference theory about the notion of the hydrographic basin, environmental fragility, environmental vulnerability (history and conceptions) and the theory of geosystems (Russian and French) on the impact of urbanization on the environment; this argument realizes a generic presentation of the notions, approaches and the problem. However, nothing is said about "how" the notion of hydrographic basin or the concepts of landscape and geosystemic theory can be used to examine the specific research question. Consequently, the approaches, concepts and notions need to direct the reflection and discourse to the reading of the specific reality studied and not stay in a generic and discursive movement. Thus, the most appropriate inquiry would be based on the following questions: How could the notion of a hydrographic basin be considered to study the environmental repercussions of urban expansion (a phenomenon that is not limited to a basin)? How can the concept of landscape provide elements to scrutinize and operationalize environmental impacts, riverpollution, erosion, biodiversity decline and pressure on springs? How can geosystems theory (under a strong naturalistic influence) fit the study of the environmental repercussions of urban expansion? How can the humanistic approach be used to study the repercussions of urbanization in rural areas? The same can be understood in terms of the geo-economical approach (by the notions of planning, space, and the structuralist and functionalist approaches). The question is: How can these approaches, theories and concepts be used as a method to answer the specific questions in research? How effective is it to answer the specific questions of a research study?

In the theory/empirical evidence relationship, the research problem is thus the background that guides the research, but it is the research questions that will direct the theoretical inquiry of specific approximation with the empirical. It is guided by the specific questions that the broad theoretical discussion relates to the empirical reality and can thus offer elements to construct a form or method to approach it. Thus, it is possible that the theoretical discussion offers methodological elements and directions for how to deal with the empirical side of the research.

\section{THE CONSTRUCTION OF THE RELATIONSHIP THEORY-EMPIRE: THE THEORETICAL- METHODOLOGICAL PATH}

Based on research questions, for the theoretical discussion to offer elements to study the empirical, it is necessary that the readings and reflections of a study constantly relate to field data. It is as a result of this dialogue that methods of study are constructed. It has been observed in many postgraduate studies that the reading and construction of a theoretical reference are realized before the field trips; that is, they are elaborated before coming into contact with the empirical part of the work. We suggest that the contact with the empirical be constant, starting at the beginning of the research. It is thus in this movement of confrontation between theoretical research and empirical reality that the theoretical framework must be constructed: At the beginning, middle and end of the research. Of course, in the final stage of the research, this movement ceases; to 
have the 'last field trip' as the ultimate action, and then to end the work. What is being emphasized here is the need for the theoretical-methodological construction of the works to be done in dialogue with the empirical questions. Although the general research problem already guides the readings and elaborations, it is the empirical elements, under the reference of the research questions, that will define the specific subjects to be confronted and reflected by the theory to create the basis for the construction of the argument. In the theoretical-methodological construction, the research questions support the extraction of the empirical elements of the specific aspects actualized, which at the beginning of the research the researcher was not aware of. This forces the researcher to develop the general theory with new propositions to account for the phenomena observed, and in this sense, during the construction of the works, to advance in the movement of a test of the theory by the empirical-explicative capacity of your propositions. It is by narrowing the relation between theory and the empirical reality that the theoretical-methodological construction can advance in its propositions.

Even adopting a prior theory (Marxist, Phenomenological, Systemic, etc), a theoreticalmethodological construction must be given in the movement from theoretical to the singularity of the empirical, offering ways of reading these phenomena. The organization and connection of the chapters are fundamental for this movement to occur. The discussions of the chapters must complement each other in a prepositive way and be directed towards the research questions (and not digress from the themes). One chapter should directly suggest and support the others and offer means and directions of studying reality. The adaptation of concepts, notions and propositions of the general theory to the empirical phenomena is part of this movement. The extraction of ways to study such a reality as a result of these adaptations is the next reflexive step, precisely characterizing the reversion of theoretical considerations into methodological attitudes and specifying "how" to study the phenomena.

In dialogue with the specific research questions, the theoretical discussion will talk about the senses, agents, structural and processual aspects, classifying and discerning the scales and domains of interaction; in this way, it will present a general explanation adapted to the specific research questions. It is precisely this theoretical information that will link the dialogue with the results, influencing the obtaining data and your discussion - and in this direction, serving as a 'theoretical reference' for the discussion of the results. The methodological procedures are the practical attitudes applied in the empirical reality and are defined from the theoretical reference of the senses, agents, structures and processes that must be investigated to answer the research questions. Thus, the 'method' (theoretical-methodological path) is the reflection of how to investigate the empirical, and the methodology the practical procedures of this investigation, which will get the results. Obtaining the results will be the theoretical reference that will serve to support the discussion of these results, confronting the propositions, understandings and interpretations of reference. This confrontation will present the confirmation or refutation of the theoretical propositions, create new meanings to be incorporated, questions to be reformulated, methods to be criticized and other phenomena to be considered, thus advancing the theoretical-methodological construction and representation of empirical reality.

From this view of the theory, one can say that the meanings and agents presented and discussed in the references should be those used in the interpretation of phenomena (of the empirical area); the discerned meanings and agents will be those treated as active in the empirical study; the structures and the processes discussed in the framework will be those identified and studied in 
the empirical; the scales considered determinant in the theoretical discussion will be used to define the scope of the empirical relations, and vice-versa. From the empirical, one can say the same: The meanings and agents observed in the empirical should be those used in the reference of the theoretical discussion; the discerned empirical meanings and agents will be those treated as active in the theoretical study; the structures and processes discussed will be those identified and studied in the theoretical study; the scales considered determinant in the empirical phenomena will be used to define the scope of the theoretical relations. Therefore, the discussion of the reference theory must be directed by the research questions to build a theoretical-methodological path to guide the empirical treatment and be in constant dialogue between theory and the empirical reality.

\section{REFERENCES}

BUNGE M. 1980. Epistemologia. Curso de atualização. São Paulo: Ed. USP, 246 p.

BUTTIMER A. 1982. Apreendendo o dinamismo do mundo vivido. In: Christofoletti A, Perspectivas da Geografia. DIFEL - Difusão Editorial S.A., p. 165-193.

CHRISTOFOLETTI A. 1999. Modelagem de sistemas ambientais. São Paulo: Edgard Blucher, 236 p.

FEYERABEND P. 1993. Against Methods. New York: Ed. Verso, $279 \mathrm{p}$.

GOODE WJ AND HATT PK. 1979. Methods in Social Science. New York: McGraw-Hill Book Company, 386 p. HARVEY D. 1973. Social justice and the city. Baltimore: Johns Hopkins University Press, 336 p.

SANTOS M. 2000. O papel ativo da Geografia: um manifesto. Debate - Conferência em 04/10/2000. São Paulo, USP Auditório do Prédio de Geografia/História. Available at: https://www.youtube.com/watch?v=xpM6M08rI3E. (Accessed 20/02/2016). 